\title{
ICT system for SMART CITY
}

\author{
Robert Bryłka, Krzysztof Kazubski \\ Intergraph Polska \\ Warsaw, Poland \\ robert.brylka@intergraph.com, \\ krzysztof.kazubski@intergraph.com
}

\author{
Jan Studzinski \\ Polish Academy of Sciences, Systems Research Institute \\ Warsaw, Poland \\ studzins@ibspan.waw.pl
}

\begin{abstract}
In the paper a concept of an ICT system for complex management of whole city is presented. The ICT system called Smart City consist of several branch modules integrated by a GIS platform. The system is being developed by the Systems Research Institute (IBS PAN) in Warsaw in cooperation with Intergraph Polska.

Index Terms-Smart City, complex management of city, computer aided decisions making systems, mathematical modelling and optimization.
\end{abstract}

\section{INTRODUCTION}

The modern world trend in computerization of industrial or more generally of environmental systems means development and implementation of integrated ICT tools for complex management of whole processes investigated when the solution of technical, organizational and financial problems is taken into consideration simultaneously. Such the ICT systems have been developed and are permanently under development for instance at the Systems Research Institute (IBS PAN) in Warsaw for integrated management of communal water and wastewater networks and tested with the real data from several Polish waterworks $[1,2,3]$. The structure of these systems consists usually of a GIS (Geographical Information System), SCADA (System of Control and Diagnostics Analysis) and CIS (Customer Information System) which are integrated strictly with some modelling, optimization and approximation algorithms [3, 4]. Due to this strict cooperation under several programs all tasks of the water or wastewater net management can be automatically executed or computer supported and the tasks being solved concern the technical as well as organizational, administrative and economic problems [5].

But in scale of a whole city the independent and separated computerization of only one communal system under a lot of the subjects communally managed seems to be insufficient. The information technologies currently used enable to support the computer aided management of many objects in the same time. Because of that the last trend in development of computer aided decisions making systems displays in creation of systems which comprise in their operation many domains of city activities. Such an ICT system for a Polish city of medium scale is now under development at IBS PAN. The possibility of financial benefits resulting from such the complex computerization is particularly important for the management boards of the city governments which are elected for their several years terms by the city inhabitants. The benefits for the inhabitants are these ones of qualitative art and they concern the fullness of information about functioning of the city that the system users can win fast and in a simple and easy-going way.

ICT systems for Smart Cities have been developed or are under development worldwide for a couple of years and also in Poland there are teams consisting of staff members from scientific and research units as well as from administration offices that are dealing with concepts and applications of smart city systems. But in general there are mostly only detailed concepts of such the systems prepared without farther applications in the practice. Some other often realized cases mean development of ICT systems concerning only a small part of problems connecting with the whole city management. The problems mostly investigated in this way are dealing with different kinds of city monitoring, like streets monitoring via video cameras or traffic monitoring via traffic sensors installed in the roadways or air monitoring regarding the air pollution.

In case of our investigation the ICT system under development will deal with most of the problems connected with the complex management of a city and it will be put into operation starting at the end of 2014. Due to it the functional range of the system is wide and such the application has been until now nowhere implemented. The financial support for the system that will be developed in frame of a research project will come from the Polish National Centre for Research and Development and from the regional funds of the region in which the city being the object investigated is located. The project will be realized by the consortium grounded especially for this task and consisted of the Systems Research Institute as the project leader, of Intergraph Polska responsible for the performance of the City Portal on the GIS platform, of the Town Hall as the project beneficiary and of several city offices and enterprises which will be the users of the ICT system.

There is also an idea to develop such the ICT system for Smart City management in frame of an European research project in cooperation with some foreign partners but it seems unfortunately that no appropriate calls have been planned in the Horizon 2020 program. 


\section{THE MAIN COMPONENTS OF THE ICT SYSTEM FOR CITY MANAGEMENT}

According to the mentioned trend in development of ICT systems a concept of an integrated system for joined solution of many management tasks in city scale has been developed at IBS PAN (Fig. 1). In this system 8 domain modules are foreseen and the key module of the system is the GIS platform with its central data base. The domain modules concerned are City Portal, City Dispatcher Centre, Streets Monitoring, Traffic Monitoring, Waterworks Management, Rescue Module, Air Pollution Forecasting and Flood Threat Module (Fig. 1).

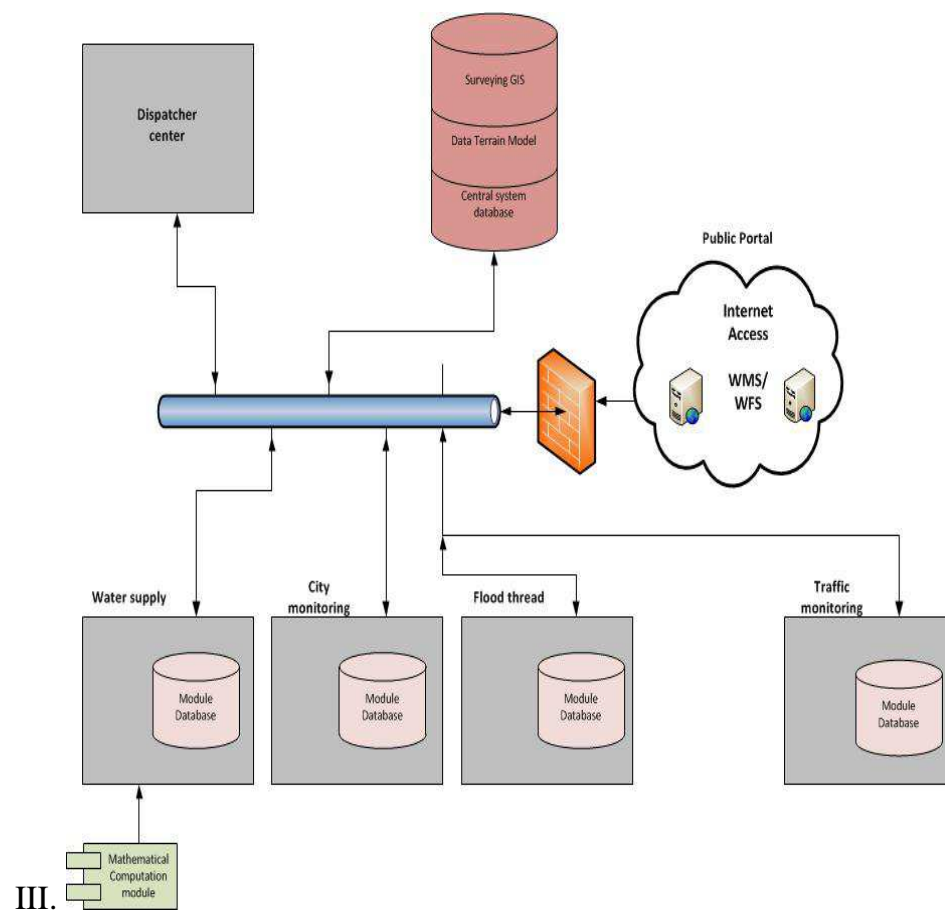

Fig. 1. Block diagram of the ICT system for smart management of a city.

Each module of the ICT system is autonomous and runs independently from each other but at the same time all modules cooperate with the GIS system using for their runs the data gained from the GIS database. Each module has got its own interface and its own database and these bases exchange the data with the GIS data base via SQL tables or service bus. In the following the short descriptions of the system modules are given [6].

\section{Modular integration}

The IST system planned will have modular architecture with a number of integration interfaces. The old-style integration based on the point-to-point connections between all system functional points does not fit to the modern functional architecture. Then there is a reason that different integration model is a must for the planned system.

The system has to square some difficult and at the first sight opposite requirements. It has to be simple but also very effective for some users, for another group is should be very accurate etc. Moreover the system will compute huge amount of data taken from several sources like offices, independent companies or enterprises etc. Some of that data may be confidential for a part of users and it should be isolated from others.

As a result the Smart City system planned will have 3-tiers integration:

1. Internal integration - integration inside every module of the system. We assume that specific modules dedicated for specific line of the business can be complex and can use big amount of very detailed data. Therefore there is integration inside each module with some subsystems cooperating, like for example SCADA, computational software, finance and CIS systems in case of the Waterworks Management module. All data supplying by these subsystems are required for proper work of the Waterworks Management module, but that data is not necessary for other modules of the whole ICT system.

2. Integration between modules - the main integration of the ICT system will provide data-flows between different system modules. It will work based on two integration solutions, i.e. integration bus and SOA (Service Oriented Architecture) [7]. The important part of that tier is data filtering.

3. External integration - that tier provides data publishing based on WMS/WFS SOA architecture (Web Map Server/Web Feature Server SOA for GIS Applications) and it provides also some points of interaction with external systems. It must provide bidirectional integration.

E.g. the Smart City system can be source of data for regional security services, but in the same time it can read data for Flood Thread Module taken from weather forecast organizations. That part of integration covers some external solutions like public www portal or mobile parts of the ICT system.

Such integration model of the ICT system enables high potential for communication with already existing and future system modules and with external systems. In addition the integration planned must be extra robust due to volume of data to be transmitted. That foundation forces to use the industry standards in that area.

Our vision of an integrated modular system is to help the owner of the system to achieve efficiently operational and strategic goals by providing seamless software capabilities, as well as transparent consumption data provided by the thirdparty services.

The service oriented architecture provides flexibility and maintainability. It enables effortless integration between services provided by different companies. Moreover it makes the whole system safer due to making it more independent from the third-party cooperators. 
Huge ICT systems, like the described one, can not be considered without expensive hardware part of the project. During operational work of the system the hardware has to be changed or modernized. The SOA architecture allows the evolution of ICT infrastructure. Robust hardware background plays a very preponderant role in the whole system. During the system live the amount of users, data and hopefully additional modules will increase and as result the ICT infrastructure will have to be changed and get more powerful. Thus all parts of the system must be able to be connected to new technological parts. At the moment SOA architecture is the most independent facing unique fast technological change in the whole IT environments.

The SOA based services will be also the data source for mobile solutions dedicated only for authorized users. Some typical SOA services are used in different systems. These examples are: routing services, sensor observation and alert services, mobile work force management, network management etc.

\section{Data consideration}

Regarding system performance and volume of the data there are some specific points that must be considered in case of a Smart City system. In order to provide quality services to citizens and communities, decision-makers should have access to different shared information from disparate sources. Business logic implemented in the system and based on accurate data has great potential of support business operations. That potential can be repacked into higher level services that could be easily understood by non-technical people for effective solving many day-to-day tasks.

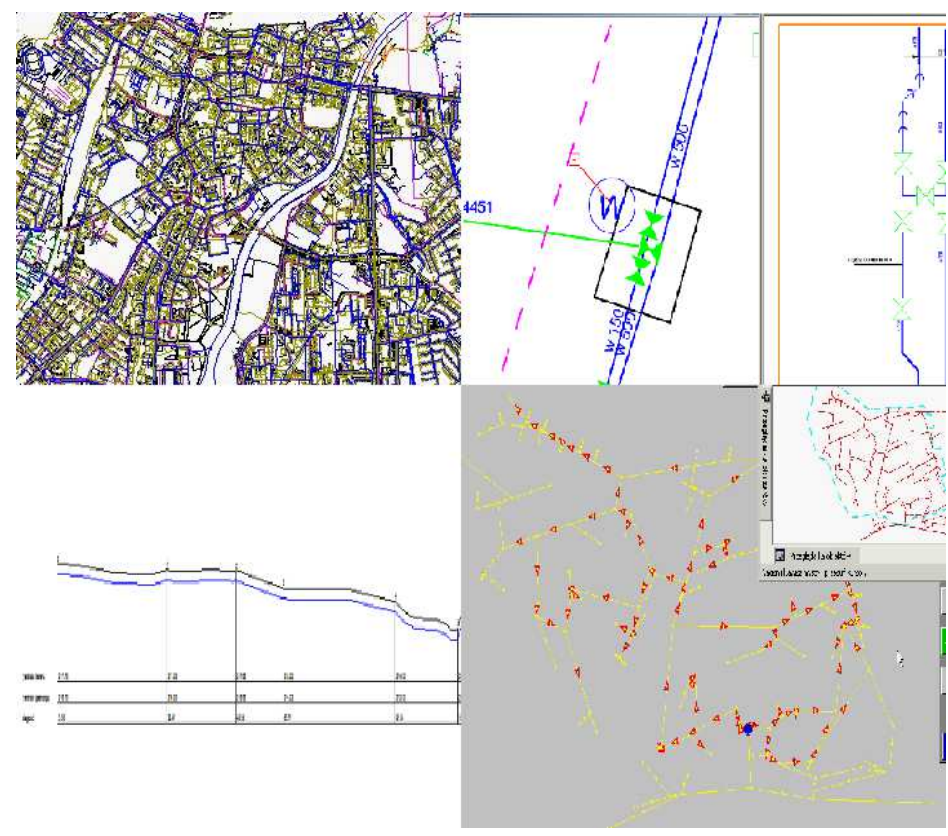

Fig. 2. From detailed to schematic view of utility network; from the top left to the bottom right: numerical map of the whole water network; water net pipe to be investigated; altitude profile of the pipe; water net hydraulic model ready for calculations.
As already was written every module of the ICT system will operate on huge data set with some very detailed data describing business specific areas. The same detail level of data which is necessary for the module operations will be probably overwhelming for users of other modules. So the view for some data must be designed in that way that the data is filtered and simplified (Fig. 2). In general the view of the data from outside of the module referred must be as simple as possible. Typically in GIS area, every module should be able to get background maps on different scale-dependent views and on the top of these maps the utility specific information will be displayed and operated. That approach provides to the idea of common background map storage with effective delivery services and in addition of the module dedicated specialized GIS levels with all required topological information, schematics etc. (Fig. 2).

\section{City Portal}

Doing the City Portal as a key module of the Smart City system is indispensable because of the necessity of consideration of the important social aspect in the end product of the project realized and also because the City Portal will be the system layer integrating all its functional modules. The City Portal will include a public part accessible for all city inhabitants and several domain modules with the restricted accesses assigned only for the city decision makers and for the relative city services (e.g. City Dispatcher Center).

The City Portal will be the main source of information for the city inhabitants as well as for the city services about the state of the city functioning, about the current or potential events or about the threats and dangers that will need interventions of the specialized city service teams.

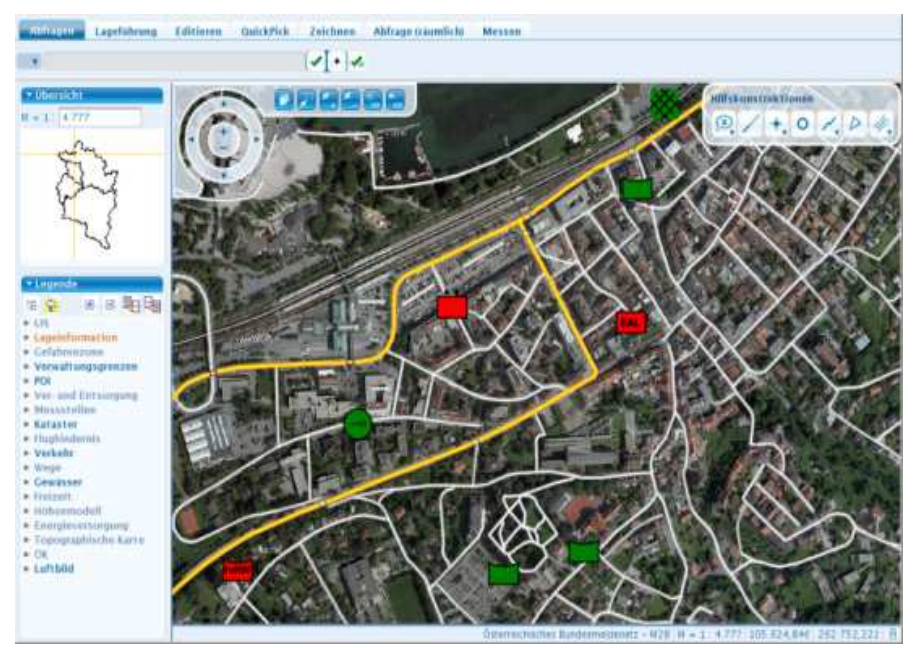

Fig. 3. Geospatial City Portal (example).

Geospatial City Portal (Fig. 3) will simplify the process of finding, connecting to, and displaying spatial data published through web services. It will ensure smooth browsing through intuitive navigation controls and technical advances such as asynchronous communication that ensures that panning and zooming are not interrupted by having to wait for servers to 
respond. The client's utility will be enhanced by additional tools, such as control of the appearance of individual map layers, and the ability to save and recall map context.

The City Portal environment will be open for crowdsourcing (crowd-sourced data). A specialized mobile application will simplify reporting for the citizens and will allow to enlist the masses to help define and locate issues such as road damages, water leaks, and more. A cloud-based service will provide integration of the crowd-sourced incident information with the City Portal.

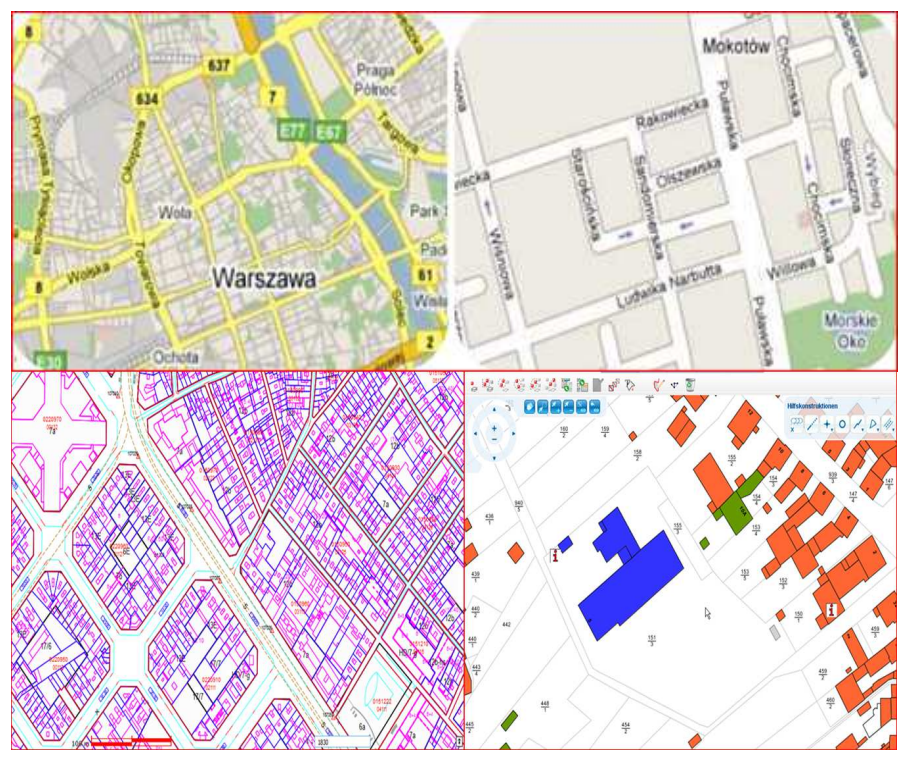

Fig. 4. Raster (at the top) and vector maps of the city accessible on the City Portal.

The information accessible on the City Portal will be mainly in form of the numerical maps generated by the GIS system being the platform of the ICT system (Fig. 4).

\section{City Dispatcher Centre}

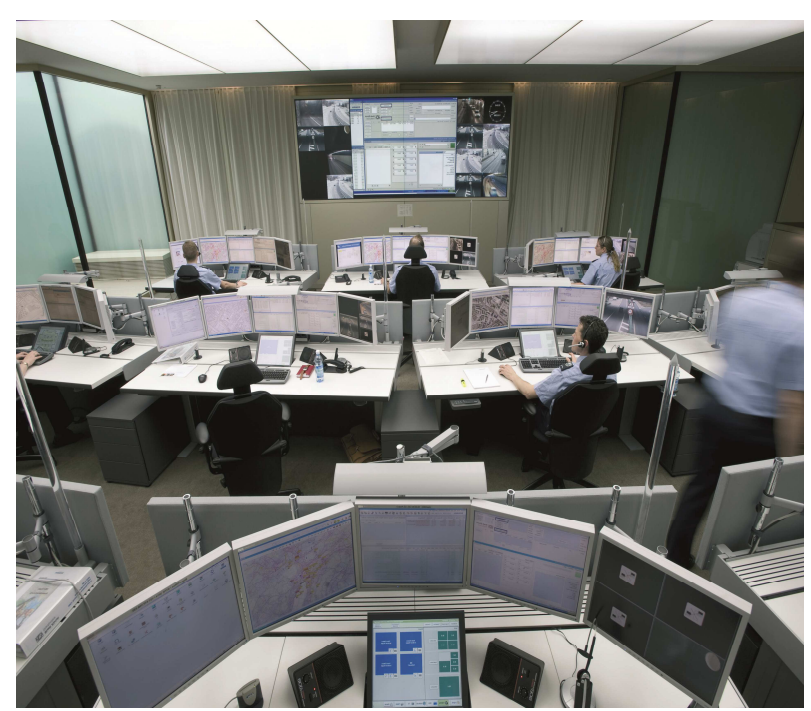

Fig. 5. City Dispatcher Centre of the ICT system.
In frame of the ICT system planned a City Dispatcher Centre will be operated (Fig. 5). The functioning of the City Dispatcher Centre will be supported by the mechanisms of the geographical attendance realized on the GIS platform of the ICT system. These support mechanisms will enable the seamless exchange of information between the remaining modules of the ICT system.

The City Dispatcher Centre (CDC) is intended as an extension of the City Portal enlarged about some additional functions of inter-modular communication. An CDC combines command and control, data visualization and sensor integration technologies into a common operating picture (Fig. 6) [8].

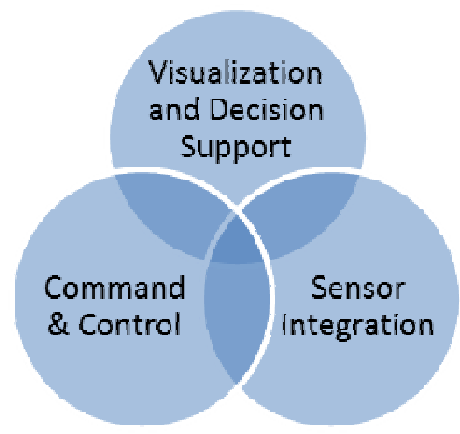

Fig. 6. Structure of functionality of the City Dispatcher Centre.

The City Dispatcher Centre has ability to create an effective common operational picture and state of situational awareness that provides operational support for an organization during normal and emergency conditions.

The predicted advantages of an City Dispatcher Centre may be summarized as follows:

- Better communications between operational areas.

- Increased opportunities for collaboration and innovation.

- The ability to form new integrated management structures.

- Improved decision making.

- Cost reductions from areas such as reduced site travel.

- The opportunity to standardize operational systems and processes.

- The creation of a platform for deployment of new technologies, e.g. automation.

- More streamlined staff recruitment, and

- Better staff retention (if a keen sense of mission and good staff relations are developed) [9].

\section{Streets Monitoring}

The Streets Monitoring module of the Smart City system is intended as classical streets monitoring system based on the technological advanced analytics mechanisms of pictures recorded and supplied by video cameras which are installed at the trouble spots of the city (Fig. 7). 
The task of this monitoring system is securing the safe living conditions for the city inhabitants. Such the monitoring systems called also as Intelligent Surveillance are worldwide under development since about 15 years for only since a such time the new IT technologies make possible to process the on line recorded pictures with relevant high speed and fidelity.

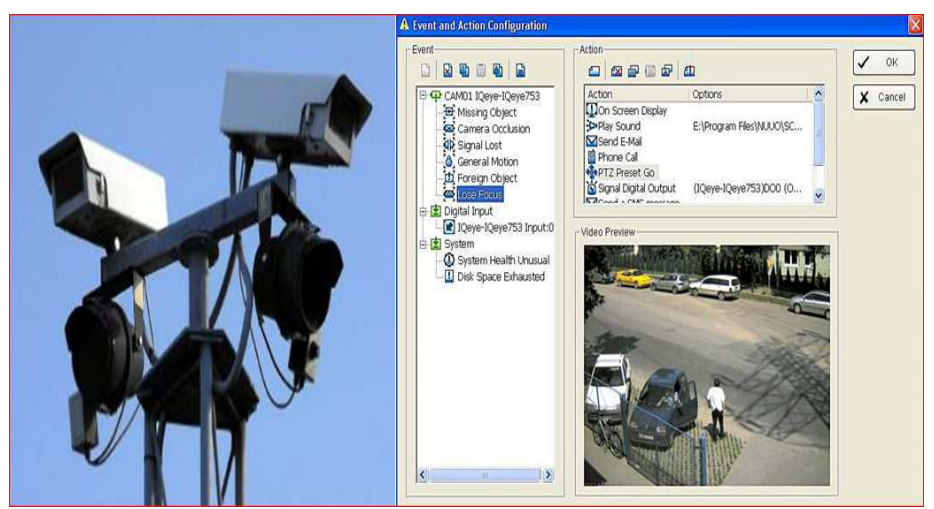

Fig. 7. City Monitoring module of the ICT system.

\section{Traffic Monitoring}

The Traffic Monitoring module uses in its operation the Streets Monitoring and a system of traffic sensors installed in the roadways of the streets. Using the sensors the Traffic Monitoring system examines in the real time the state of intensity of vehicle movements and informs the City Dispatcher Centre about the accident situations arising. This module will collect also all informations concerning the traffic events in the city reported by the city services.

As a result of the module activity the messages informing the city inhabitants about the current state and exceptional situations in the city traffic like accidents, traffic diversions or switching of some street sections will be generated and placed on the City Portal (Fig. 8).

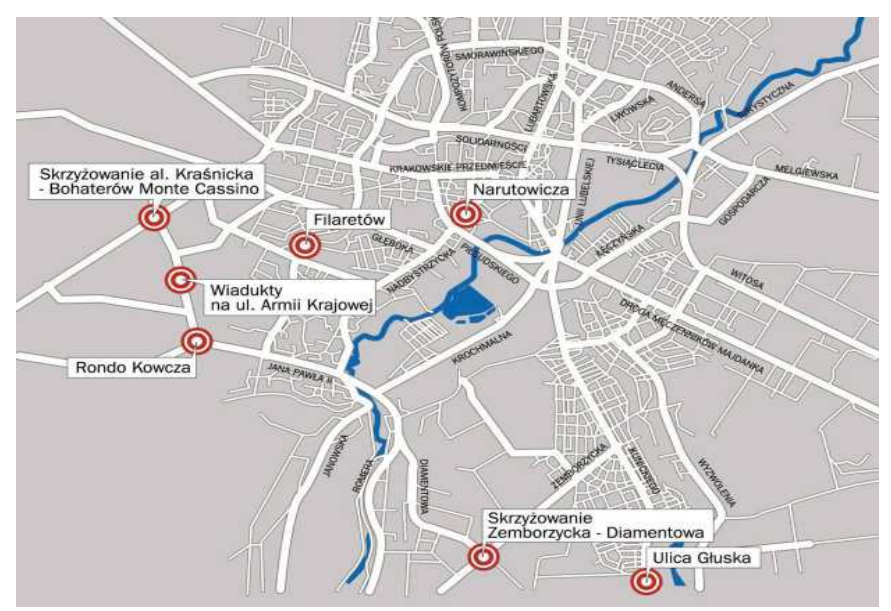

Fig. 8. Signalization of traffic jams in the city by the Traffic Monitoring module of the ICT system.

The additional task of the Traffic Monitoring module is also development of algorithms to control the road traffic and generation of some scenarios designing new re-routings in case of traffic jams occurred and on the base of recorded and collected traffic information.

The Traffic Monitoring module will also communicate the City Portal and supply it with the information about the exceptional cases in the town traffic and about the proposed or fixed re-routings or turning offs.

\section{Waterworks Management}

In frame of the Smart City system an integrated ICT system supporting the complex management of the city waterworks will be implemented. In this waterworks system the computer aided management of the water network (Fig. 9), wastewater network and the sewage treatment plant basing on the hydraulic models of the objects investigated and on some optimization algorithms will be realized $[1,2,10]$. To do it the present monitoring systems supervising the water and wastewater nets and the sewage treatment plant will be extended and with the hydraulic models and optimization algorithms together they will be integrated with the GIS system installed in the waterworks forming in this way and united ICT system.

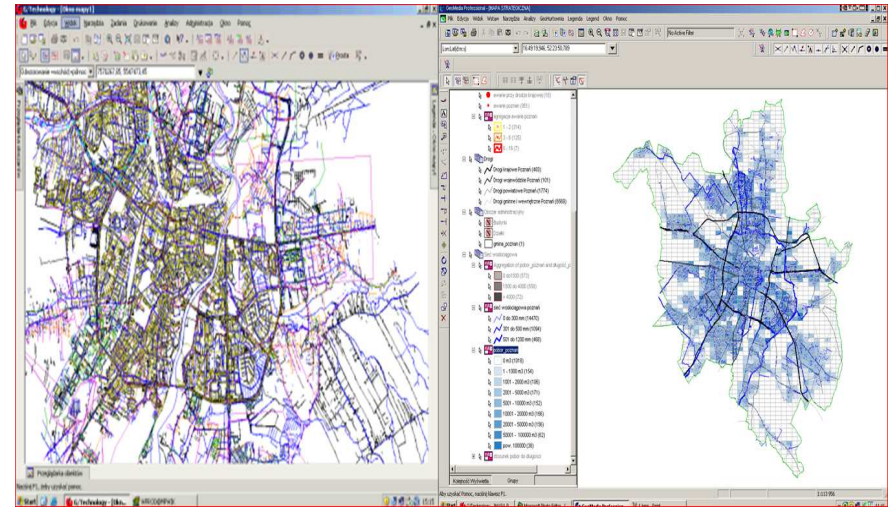

Fig. 9. Water network numerical maps accessible on the Waterworks Management module: network hydraulic graph (left) and the current water withdrawal in the network.

An ICT system for computer aided management of communal water networks by means of GIS, SCADA, mathematical models and optimization algorithms has been already developed at the IBS PAN and is under installation in some Polish waterworks, among others in Upper Silesian Waterworks which are the biggest one in Poland. Its primary structure and functionality has been presented on the ICT4S'2013 in Zurich [3] (Fig. 10).

In the ICT system for Smart City management the Waterworks Management module will include the already developed IT system for water nets extended about new systems dedicated for the wastewater network and sewage treatment plant. These three IT systems will be internal integrated based on the data base communication via SQL tables.

The main goals of the Waterworks Management module developed as a part of the Smart City system are the minimization of the operational costs of the whole enterprise 
and securing the accident-less functioning of its key objects. Some other goals that are either to be achieved with the Waterworks Management module are the improvement of the quality of the drink water produced by the water network, generation of scenarios of planning the water and wastewater nets revitalization and the environment protection by minimizing the amount of pollutions introduced to the city river by the sewage treatment plant.

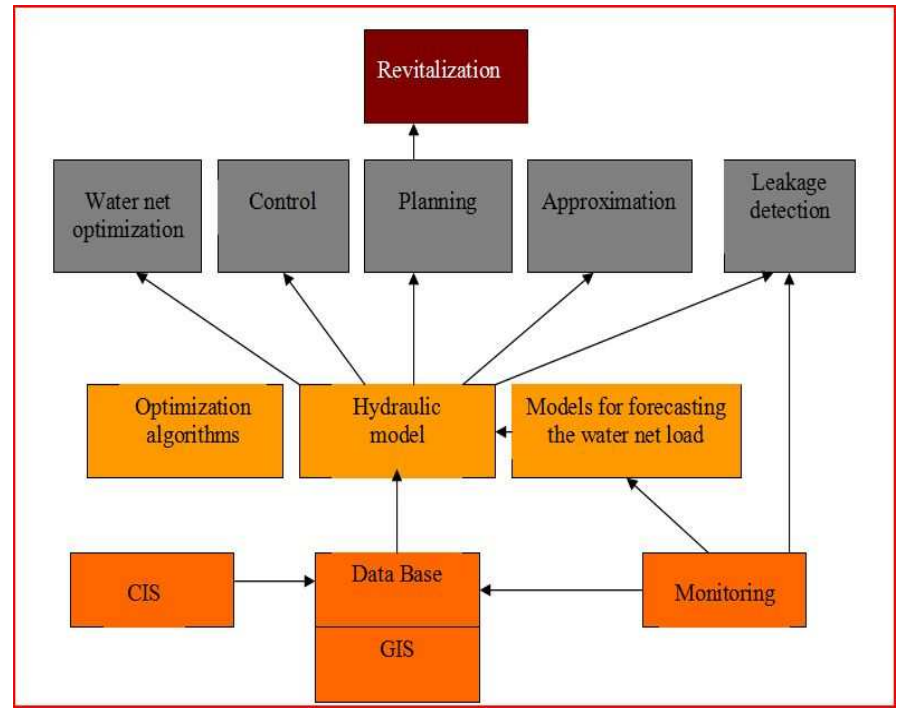

Fig. 10. Block diagram of the IT system for water networks management.

\section{Rescue Module}

The Rescue Module will operate the city infrastructure and in our current concept of the Smart City system in the first phase of its development there will be operated the city water hydrants supporting fire protection operations. Generation of maps showing the spheres of hydrants activity in scale of the whole city or more detailed for the selected city areas (Fig. 11) will be of great importance for fire brigades executing the firefighting.

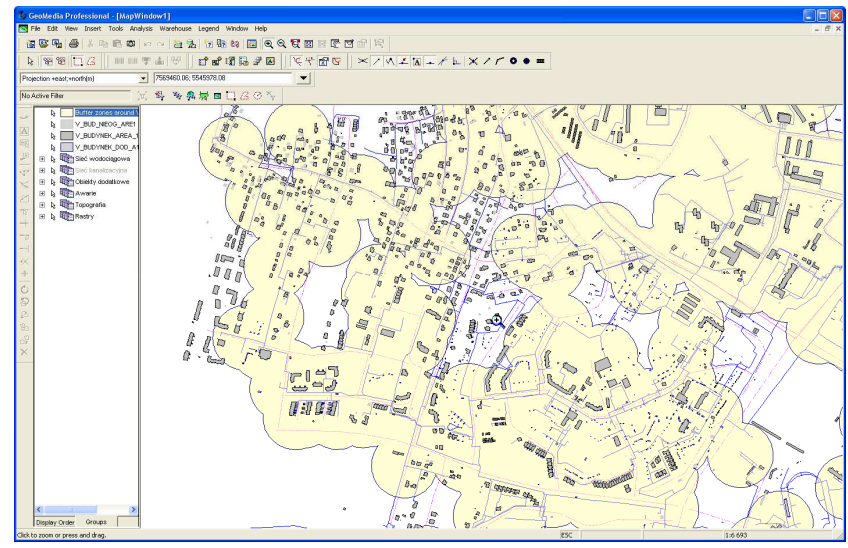

Fig. 11. Map of the hydrant coverage generated by the Rescue Module.

An additional task of the Rescue Module is to support the controlling and combatting the crisis situations in the city like streets accidents or chemical disasters. The latter events can occur in the city because one of the biggest Polish refineries is located there and the cars or railways transports of chemical dangerous materials are passing very often the city communication routes.

\section{Air Pollution Forecasting}

The task of the Air Pollution Forecasting module is computer aided modelling and forecasting of emission of greenhouse gases and air pollutions in the city region which are produced by the exhaust fumes being the result of the road traffic and trucking and are generated by the local heating plants and boiler houses and by the oil refinery mentioned above. On the base of the modelling results concerning the air contamination some forecast analyses regarding the impact of the pollutions emission on the health state of the city inhabitants will be prepared.

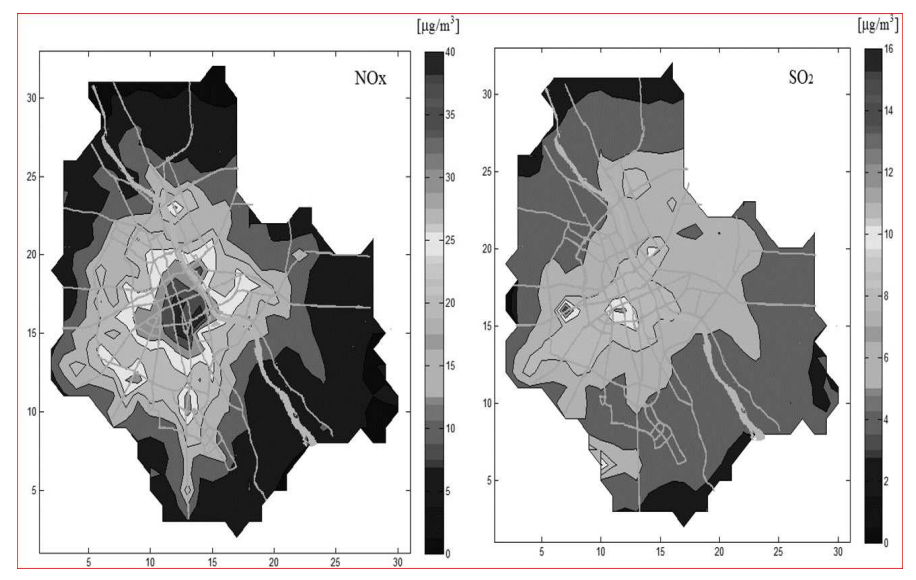

Fig. 12 Maps of concentration of NOx and SO2 in the city atmosphere generated by the Air Pollution Forecasting module.

The main task of this module is informing the city inhabitants about the potential health threats caused by the greenhouse gases and other air pollutions and if such adverse cases will arise then preparing for the city decision makers recommendations and proposals of actions that could be undertaken against these events.

Exemplary maps generating by the Air Pollution Forecasting module and comparing the distributions of the typical traffic-related pollution (NOx) and the pollution strongly depending on other emission categories (SO2) are shown in Fig. 12 [11].

\section{Flood Threat Module}

The task of the Flood Threat Module is monitoring of the water level in the river passing the city and forecasting the potential flood threats if the river dam protecting the city would have been broken.

The computer simulation of overflowing the right part of the city which is especially threatened by the flood way because of its low laying will be executed by means of a GIS system and a 3D numerical model of the area investigated produced by GIS (Fig. 13). 


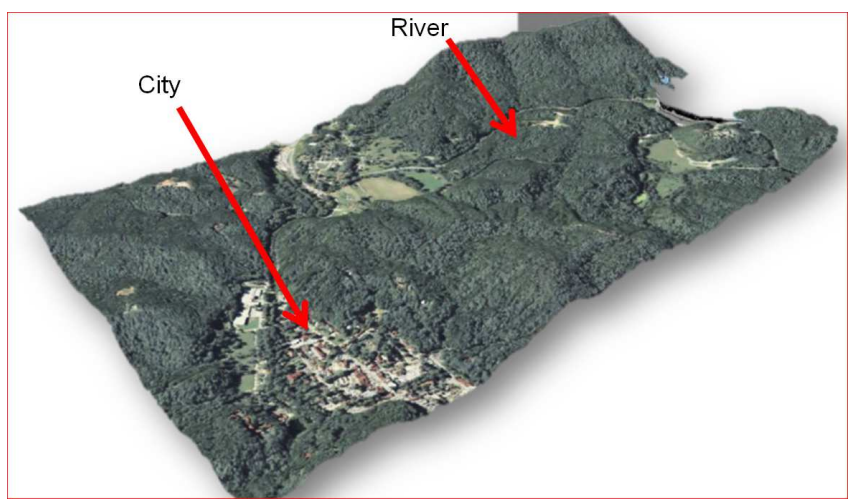

Fig. 13. Numerical 3D model of city and river area generated by the Flood Threat Module.

\section{CONCLUSIONS}

The main goal of the module operation is to warn relatively early the inhabitants of the potential threatened areas about the possible flood danger.

The article describes a concept of integrated ICT system for supporting city management. The concept is based on the Smart City idea and has been developed at the Systems Research Institute (IBS PAN) in Warsaw in cooperation with Intergraph Polska. The project described is planned to be implemented in 2014 and introduced in a middle size Polish city with population of about 200.000 habitants. System has got an open, modular architecture.

Currently planned modules support mainly areas of water supplying and wastewater treatment systems, fire and flood protection and city monitoring. Water supplying system is enriched by mathematical models of computer networks computation and optimization for both water and sewage networks. Similar support is possible in the future for other utility networks like gas, district heating and power.

Integration between modules will be implemented on database level which means sharing information (tables, views) directly between specialized local databases. E.g. the database of the water network module will read the data describing the network and its parameters from surveying GIS database and after this transfer the module programs will use the data for water net hydraulic calculation or optimization. That approach makes modules communication simple, reliable and seamless executable. In addition encapsulated parts of data assure high level of security for the whole data storage.

\section{ACKNOWLEDGMENT}

The paper presented has been realized in frame of the research project of the Polish National Centre for Research and Development (NCBiR) co-financed by the European Union from the European Regional Development Fund, Sub-measure 1.3.1. "Development Projects"; project title: "IT system supporting the optimization and planning of production and distribution of water intended for human consumption in the sub-region of the central and western province of Silesia"; project ref no POIG.01.03.01-14-034/12.

\section{REFERENCES}

[1] A. Służalec, J. Studzinski and A. Ziolkowski, "Optimization of sewage structure in the integrated system for sewage design, management and revitalization - MOSKAN". In: Simulation in Umwelt- und Geowissenschaften (J. Wittmann, M. Mueller, Hrsg.), ASIM-Mitteilung AM 146, 2013, 203-210.

[2] M. Stachura, B. Fajdek and J. Studzinski, "Model based decision support system for communal water networks". ISC'2012 Conference, Brno.

[3] J. Studzinski "IT system for computer aided management of communal water networks by means of GIS, SCADA, mathematical models and optimization algorithms". In: Proceedings of the ICT for Sustainability Conference: ICT4S, Zurich, February 14-16, 2013, 123-127.

[4] S. Saegrov, "Care-W - Final Report". Research Report, SINTEF, Trondheim 2004.

[5] J. Studzinski, "Some algorithms supporting the computer aided management of communal water nets". In: Modelling and Simulation'2009 (Marwan Al-Akaidi, Ed.) EUROSIS-ETI Publication, Leicester, UK, 2009, 345-349.

[6] D. Ciesla, "Smart City - Smarter Decisions". Intergraph commercial documents, Warsaw 2014.

[7] "Service-Oriented Architecture Vision and Roadmap". Intergraph commercial documents. Huntsville 2013.

[8] "Solutions for Safe Cities. Concepts for Integrated Operations Centers". Intergraph commercial documents. Huntsville 2013.

[9] "Integrated Operations Centers". Intergraph commercial documents. Huntsville 2011.

[10] J. Studzinski, "Wastewater treatment plant maintenance using the plant mathematical models". In: Quality, Reliability and maintenance, $4^{\text {th }}$ International Conference QRM'2002 (G.J. McNulty, ed.), PEP London, 137-140.

[11] P. Holnicki, "Uncertainty Analysis in Urban Scale Forecasts of Air Quality". In: Modellierung und Simulation von Ökosystemen (Nguyen Xuan Thinh, ed.), Workshop Kölpinsee 2013, Shaker Verlag, Aachen. 